\title{
Development of an early detection method for white root disease of rubber: A preliminary investigation
}

\author{
T H P S Fernando*, C K Jayasinghe* and D Siriwardene* \\ *Rubber Research Institute of Sri Lanka, Dartonfield, Agalawatta, Sri Lanka
}

Received 30 December 2011; Accepted 14 June 2012

\begin{abstract}
White root disease is the most destructive root disease of rubber in Sri Lanka and the rubber growers are confronted with the problem of early detection of this disease. The present study was aimed at investigating the possible early detection techniques to increase the effectiveness of chemical control programmes. The artificial inoculation of the plants was faster with naturally infected root inocula than the artificially prepared inocula. Fourteen weeks after mulching, all the plants under investigation showed rhizomorphs on the collar region while only $30 \%$ of the infected plants kept without mulching showed the rhizomorphs on the collar region. The rapid upward movement of the fungus in the presence of a mulch is shown to be useful for early detection of the white root disease.
\end{abstract}

Key words: early detection, mulching, white root disease

\section{Introduction}

White root disease caused by Rigidoporus microporus (Fr.) Overeem, is the most destructive root disease of rubber in Sri Lankan rubber plantations (Liyanage, 1977; 1978; 1980 \& Liyanage et al., 1977; Peries, 1981; Jayasinghe et al., 1994; 1995; Fernando, 2009). Hence, the control of the disease is vital for a sustainable rubber plantation industry. This soil borne fungus affects both mature and immature clearings killing the trees and spreading towards the adjoining healthy trees. The disease incidence on rubber is high in wet areas and the fungus has also been detected commonly in tropical crops like tea, coffee, jak, cinnamon and oil palm (Fox 1977; Johnston, 1989).

White root disease has been identified as one of the main causes for the loss of trees during the immature period resulting in unproductive bare patches in rubber plantations. In immature plantations, this disease can be controlled by drenching the recommended systemic fungicides such as tebuconazole (Folicur, 250 EC, Bayer) or hexaconazole (Anvil, 5 EC, Rallis) (Jayaratne et al., 2001). 
However, the success of the recovery rate would depend on the severity of the infection. Therefore, the early detection of the disease is of vital importance in the efficient chemical control of white root disease.

The above ground symptoms on leaves of infected rubber trees include the development of slightly off - green discolour which turns yellowish. These leaves then curve downward and buckle resembling typical wilting symptoms. At later stages, leaves become orange reddish (the color may show slight variations depending on the clone) and totally defoliate within a short period. In some trees, premature flowering and off seasonal pod set is also seen. Fruit bodies develop during the advanced stage of the disease at the collar of the trees, and are more abundant during the wet weather (Perera, 1983; Jayasinghe et al., 1995).

White root disease has become the most important disease of rubber and during the recent past it has caused more losses than all the other pests and diseases of rubber (Ismail \& Azaidin, 1985). Despite the severity of the losses this disease causes, growers pay little attention at the time of pre-planting when the disease occurrence can be prevented by adopting the correct cultural practices with the timely use of chemical treatments. It is only after a few years that the repercussions of such negligence becomes evident. Moreover, the inability to identify the disease at early stages increases economic losses and the planters are continually confronted with this problem (Jayasinghe, 2010; Fernando et al., 2010; Romruensukharom et al., 2010). Therefore a trial was started to improve early detection techniques to diagnose white root disease in rubber plantations.

\section{Materials and Methods Plant materials}

Forty poly bagged plants of the clone RRIC 121 were maintained at Dartonfield Estate, RRISL.

\section{Isolation of the organism}

Infected roots of Hevea brasiliensis collected from Dartonfield Estate, Agalawatta was used to isolate $R$. microporus. Surface sterilization was by using $0.01 \%$ a.i. $\mathrm{HgCl}_{2}$ solution, for two minutes. A pure culture of the fungus was obtained through fungal tip isolations. The cultures were maintained on Malt Agar (MA) at room temperature $\left(28 \pm 2{ }^{\circ} \mathrm{C}\right)$ under normal light and dark regimes. This isolate of the fungus (isolate KT) was used throughout the study.

\section{Preparation of the R. microporus inocula from rubber tree roots}

Freshly cut $1.0-1.5 \mathrm{~cm}$ thick rubber tree roots were washed thoroughly under running tap water. Soil particles adhering to the surface were removed. Then $8.0 \mathrm{~cm}$ length root pieces were cut and soaked in distilled water for $1 \mathrm{~h}$ and 
autoclaved for $45 \mathrm{~min}$. at $121{ }^{\circ} \mathrm{C}$ in $500 \mathrm{ml}$ glass beakers covered with tin foil. $R$. microporus (isolate KT) was grown on MA in $9 \mathrm{~cm}$ diameter Petri dishes until the colony margin reached the edge of the plates. Three mycelial plugs of about $4 \mathrm{~cm}^{2}$ were cut from the margins of the culture plates and transferred aseptically to the autoclaved roots in the beakers. The beakers were sealed with tin foil and incubated at RT.

\section{Natural inocula from diseased rubber plants}

Rubber root pieces $(1.0-1.5 \mathrm{~cm}$ thick) that were naturally infected with $R$. microporus were used. Roots were obtained from large diseased trees on the day of the experiment or on the previous day. They were cut into $8.0 \mathrm{~cm}$ long pieces.

\section{Artificial inoculation of the poly bag plants}

Poly bag plants were maintained till they were two whorled and transplanted in to the field. These plants (10 plants for each treatment) were separately inoculated with artificial or natural inocula prepared as described above. Four pieces of the inoculum were kept at the four sides of the plant at the time of planting to inoculate each plant. The time taken for the disease establishment was recorded.

\section{Detection of the disease}

Another set of plants (forty in number) were inoculated and kept for $11 / 2$ months for the establishment of the disease. Then twenty plants were subjected to mulching. Leaves of Gliricidia Sp. and Mucuna Sp. were placed around the collar region as the mulch. Five $\mathrm{Kg}$ of the mulch were applied for each plant. Observations were made at two week intervals after 1 month of preliminary incubation period. Collar of the plants were examined for the presence of fungal rhizormorphs.

\section{Results and Discussion}

\section{Establishment of the disease}

Observations on the disease establishment occurred earlier and faster when plants were inoculated with naturally infected root inocula. After four weeks of inoculation with natural inocula, $50 \%$ of the plants showed the infection at the bottom of the tap root. After 6 weeks of incubation period, $90 \%$ of the plants showed the infection in the plants which were inoculated with the natural inocula while only $60 \%$ of the plants were found infected after 8 weeks of incubation when inoculated with the artificially prepared inoculum (Table 1). 
Table 1. Disease establishment upon artificial inoculation of plants with natural/artificial inocula

\begin{tabular}{ccc}
\hline \multirow{2}{*}{$\begin{array}{c}\text { Time } \\
\text { (weeks) }\end{array}$} & \multicolumn{2}{c}{$\begin{array}{c}\text { \% inoculated trees showing } \\
\text { symptoms* }\end{array}$} \\
\cline { 2 - 3 } & $\begin{array}{c}\text { Inoculum } \\
\text { from culture }\end{array}$ & $\begin{array}{c}\text { Inoculum from } \\
\text { infected roots }\end{array}$ \\
\hline 2 & 0 & 0 \\
4 & 0 & 50 \\
6 & 40 & 90 \\
8 & 60 & 90 \\
\hline
\end{tabular}

* Presence of the well established rhizomorphs on the tap root

\section{Early detection of the disease}

The detection of the disease was done by the examination of the collar region. Till 8 weeks, no plants showed any rhizomorphs on the collar region (Table 2). But 10 weeks after mulching, $40 \%$ of the plants showed rhizomorphs at the collar region while there was no such observation in the infected plants without the mulch (Table 2). Twelve weeks after mulching, $80 \%$ of the plants showed the fungal growth while after 14 weeks all plants under investigation were having rhizomorphs on the collar region. The plants infected and kept without mulching did not show any rhizomorphs on the collar region till after 12 weeks. After 14 weeks of incubation $30 \%$ of the plants without mulching showed the infection on the collar region while one of these plants were showing foliar symptoms too.

The systematic disease control based on detection of the fungal growth by routine rounds of collar inspection after the appearance of foliar symptoms has become the practice in Sri Lankan rubber plantations. The control of the disease by chemical drenching depends on the recognition of infected plants through the above ground symptoms (Nandiris et al., 1983; Jayasinghe, 2010), hence the first trees to be detected with the disease are usually beyond saving.

Table 2. Detection of the white root disease upon mulching

\begin{tabular}{ccc}
\hline & \multicolumn{2}{c}{ \% inoculated trees showing symptoms* } \\
\cline { 2 - 3 } Time (weeks) & Planting with the mulch & Plants without the mulch \\
\hline 4 & 0 & 0 \\
6 & 0 & 0 \\
8 & 0 & 0 \\
10 & 40 & 0 \\
12 & 80 & 10 \\
14 & 100 & 30 \\
\hline
\end{tabular}

* Presence of the rhizomorphs at the collar region 
The fungal mycelium appears to grow superficially as rhizomorphs on Hevea roots. It has been reported (Fox, 1977) that this epiphytic mycelium always grows on the collar region much before fungal penetration occurs. This time gap can be effectively used to detect the disease early. Chemical control too would be more efficient if the infection is detected at early stages. However, further investigations are required to assess the reasons for the rapid upward movement of the pathogen and also to demonstrate its applicability under natural field conditions.

\section{Acknowledgement}

This project is partially founded by National Research Council (Grant No. 11 - 39). Their financial support is gratefully acknowledged. Authors thank Mrs Madushani Lanka for word processing.

\section{References}

Fernando, T H P S, Jayasinghe, C K, Silva, W P K and Wijeratne, C (2010). Management of white root disease: special reference to infected Mucuna cover crop. Proceedings of the International Workshop on White Root Disease of Hevea Rubber (Eds. C K Jayasinghe, W P K Silva and T H P S Fernando), 72-77pp.

Fox, R A (1977). The impact of ecological, cultural and biological factors on the strategy and costs of controlling root disease in tropical plantation crops as exemplified by Hevea brasiliensis.
Journal of the Rubber Research Institute of Sri Lanka 54, 329-362.

Ismail, $\mathrm{H}$ and Azaidin, M Y (1985). Interaction of sulphur with soil $\mathrm{pH}$ and root diseases of rubber. Journal of Rubber Research Institute of Malaysia 33 (2), 59-69.

Jayaratne, R, Wettasinghe, P C, Siriwardena, D and Peiris, P (2001). Systemic fungicides as a drench application to control white root disease of rubber. Journal of the Rubber Research Institute of Sri Lanka 84, 1-17.

Jayasinghe, C K, Jayasuriya, K E and Fernando, T H P S (1995). Pentachlorophenol - effective and economical fungicide for the management of white root disease caused by Rigidoporus lignosus in Sri Lanka. Journal of the Rubber Research Institute of Sri Lanka 75, 61-70.

Jayasinghe, C K (2010). White root disease of the rubber tree: An overview. Proceedings of the International Workshop on White Root Disease of Hevea Rubber (Eds. C K Jayasinghe, W P K Silva and T H P S Fernando), 1-8.

Johnston, A (1989). Diseases and pests. In: Rubber. Pp. 415-458 (Eds. C C Webster and W J Baulkwill) Longman Scientific and Technical New York.

Liyanage, A de S (1977). Rubber. In: Soil Borne Diseases of Tropical Crops. pp. 331-347 (Eds. R J Hillock and J M Waller). $\mathrm{CAB}$ International, Wallingford, UK.

Liyanage, G W, Liyanage, A de S, Peries, O S and Halangoda, L (1977). Studies on the variability and pathogenicity of Rigidoporus lignosus. Journal of the Rubber Research Institute of Sri Lanka, 54, 363-372. 
Liyanage, A de S (1978). Review of the Plant Pathology and Microbiology Department, Annual Review of the Rubber Research Institute of Sri Lanka, 1978, 66-98 pp.

Liyanage, N I S (1980). The distribution and control of White root disease caused by Rigidoporus lignosus on Hevea in Sri Lanka. MSc Thesis, University of Sri Jayawardanapura, Sri Lanka.

Perera, K V P M (1983). An integrated approach to the control of white root disease caused by Rigidoporus lignosus on Hevea in Sri Lanka. MSc Thesis, University of Sri Jayawardanapura.

Peries, O S (1981). The management problems of root diseases on rubber estates. Journal of National Institute of Plantations Management 1 (1), 54-56.

Romryensukharom, N, Chanruang and Rodesuohit, A (2010). Current status and management strategies of white root disease in Thailand. Proceedings of the International Workshop on White Root Disease of Hevea Rubber (Eds. C K Jayasinghe, W P K Silva and T H P S Fernando). 14-16pp.

Address for correspondence: $\mathrm{Dr}$ (Mrs) $\mathrm{T} \mathrm{H}$ P S Fernando, Assistant Plant Pathologist, Rubber Research Institute of Sri Lanka, Dartonfield, Agalawatta, Sri Lanka. e-mail: thpsfernando@yahoo.com 